\title{
Preventively enteral application of immunoglobulin enriched colostrums milk can modulate postoperative inflammatory response
}

\author{
Klaus Orth ${ }^{1}$, Wolfram Trudo Knoefel ${ }^{2}$, Martijn van Griensven ${ }^{3}$, Christiane Matuschek ${ }^{5}$, Matthias Peiper ${ }^{1,6}$, \\ Holger Schrumpf ${ }^{4}$, Peter Arne Gerber ${ }^{4}$, Wilfried Budach ${ }^{5}$, Edwin Bölke ${ }^{5}$, Bettina Alexandra Buhren ${ }^{4}$ \\ and Matthias Schauer ${ }^{2 *}$
}

\begin{abstract}
Several studies demonstrated acute inflammatory response following traumatic injury. Inflammatory response during surgical interventions was verified by a significant increase of endotoxin plasma levels and a decrease of the endotoxin neutralizing capacity (ENC). However, the incidence of elevated endotoxin levels was significantly higher (89\%) than detected bacterial translocation (35\%). Thus parts or products of Gram-negative bacteria seem to translocate more easily into the blood circulation than whole bacteria. Along with the bacterial translocation, the inflammatory response correlated directly with the severity of the surgical intervention. In comparison after major and minor surgery Interleukin-6 (IL-6) and C-reactive protein (CRP) was also significantly different. Similar effects in mediator release were shown during endovascular stent graft placement and open surgery in infrarenal aortic aneurysm. Open surgery demonstrated a significant stronger endotoxin translocation and a decrease of ENC. Strategies to prevent translocation seem to be sensible. Colostrum is the first milk produced by the mammary glands within the first days after birth. It contains a complex system of immune factors and has a long history of use in traditional medicine. Placebo-controlled studies verified that prophylactic oral application of immunoglobulinenriched colostrum milk preparation diminishes perioperative endotoxemia, prevents reduction of ENC and reduces postoperative CRP-levels, suggesting a stabilization of the gut barrier. This effect may be caused by immunoglobulin transportation by the neonatal receptor FcRn of the mucosal epithelium.

In conclusion, there is an association of perioperative endotoxemia and the subsequent increase in mediators of the acute phase reaction in surgical patients. A prophylactic oral application of colostrum milk is likely to stabilize the gut barrier i.e. reduces the influx of lipopolysaccharides arising from Gram-negative bacterial pathogens and inhibits enterogenic endotoxemia. This appears to be a major mechanism underlying the therapeutic effect in patients at risk for Gram-negative septic shock.
\end{abstract}

Keywords: Inflammatory response, Endotoxin translocation, Acute phase response

\section{Review}

Multiple studies have demonstrated endotoxin as the most crucial pathogenic factor of Gram-negative bacteria and its role in Gram-negative sepsis [1-20]. Endotoxemia was shown to occur often following traumatic injury and shock, and in a variety of chronic diseases. Notably,

\footnotetext{
* Correspondence: Matthias.Schauer@med.uni-duesseldorf.de

${ }^{2}$ Medical Faculty, Department of General, Visceral-, and Pediatric Surgery, Heinrich Heine Universität Düsseldorf, Germany University of Düsseldorf, Dusseldorf, Germany

Full list of author information is available at the end of the article
}

surgical interventions are also known to be associated with an increased release of inflammatory mediators, depressed immune function and increased susceptibility to subsequent infection (Figure 1). Various studies have shown a correlation between the extent of the surgical intervention and the inflammatory response [4,21-24]. Herein, the postoperative acute-phase reaction is induced by the translocation of bacterial products in the gut causing an inflammatory response with a stress reaction and secretion of catecholamines [18,25]. Likely, endotoxin translocation plays a major role in triggering

\section{() Biomed Central}




\section{Endotoxin as a trigger of the acute phase reponse}

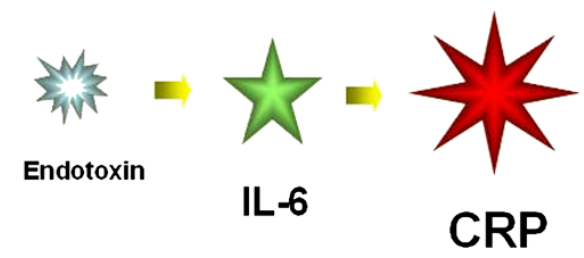

\section{Reduction of Less Endotoxemia? acute phase reponse?}

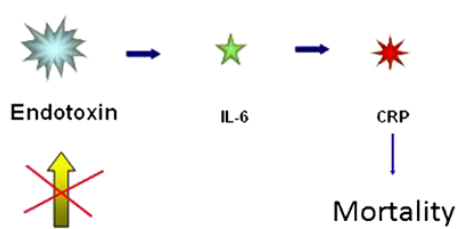

Figure 1 Interaction of endotoxin translocation and acute phase response. Diminished acute phase response in patients with less endotoxin translocation by immunoglobulin impact.

infectious complications in trauma and surgical patients $[26,27]$. Preventive protection of the mucosal barrier functions by selective decontamination with antibiotics and nutritional strategies have proven to be beneficial [4,22,28-32]. Furthermore, the enteral applications of an immunoglobulin-enriched colostrum preparation stabilize the gut barrier and diminish the peri- and postoperative endotoxin translocation and consecutively, the acute phase response (Figure 1) [22,33] (Table 1).

Colostrum has a long history of medicinal use. It is the first milk produced by the mammary glands within the first days after birth. Bovine colostrum is homologous to human colostrum, although the protein content is about twenty-, and the amount of immunoglobulin (Ig)G about ten-times higher than that of the human equivalence $[41,42]$. Bovine colostrum is accepted for human use and can easily be produced in large quantities [41]. It contains large amounts of immunological factors to support growth and immune maturation of the digestive tract and provides passive immunity until the newborn has synthesized its own active immune defense system [41,43-48]. Beside nutrients such as carbohydrates, amino acids, fat, vitamins, and minerals colostrum contains Ig, including IgG, IgM and IgA, which may provide a defense in both the treatment and prevention of viral and bacterial infections $[34,49,50]$. Bovine IgG from colostrum or milk can be effective as a means of providing passive immunity to protect animals and humans from diseases. The immunoglobulins found in milk and the transfers of passive immunity from mother to neonate (Figure 2) have been reviewed by a number of authors, with a partial listing of references [50-68].

The inflammatory response with its adverse aspects still remains an only partially understood, unresolved problem after large surgical interventions. However, the use of monoclonal and polyclonal antibodies in therapy in humans has made them the fastest-growing protein pharmaceutical agent. Our objective was to re-evaluate postoperative endotoxemia, its impact on postoperative inflammatory response and the interaction of colostrum milk immunoglobulin on the postoperative course as a possible treatment.

\section{Inflammatory response during abdominal, general and vascular surgery}

Boelke et al. [21] measured plasma endotoxin levels, endotoxin neutralizing capacity (ENC) and plasma levels of endotoxin-binding proteins (transferrin, alpha-2-macroglobulin, albumin, apo-A, apo-B, IgG, IgA and IgM) in

\section{Table 1 Summary of the crucial literature}

\begin{tabular}{|c|c|c|}
\hline$\overline{[4]}$ & Boelke E et al.; Wien Klin Wochenschr 2002 & $\begin{array}{l}\text { Immunoglobulin-enriched colostrum milk preparation reduces endotoxin translocation and } \\
\text { acute phase response in cardiac patients. }\end{array}$ \\
\hline [7] & Hsiao HB; Shock 2011 & Kinsenoside suppresses LPS-stimulated inflammatory reactions \\
\hline [22] & Bolke E; Angiology 2001 & Changes of gut barrier function during cardiac surgery \\
\hline [34] & Struff WG; Int J Clin Pharmacol Ther 2007 & $\begin{array}{l}\text { Inhibition of intestinal LPS absorption measured after bovine colostrum milk application } \\
\text { diminises IL-6 and CRP }\end{array}$ \\
\hline ] & Deitch EA; Front Biosci 2006 & The gut-lymph hypothesis, reduction of endotoxin binding protein in surgery patients \\
\hline [36] & Brandtzaeg P; Springer: New York, NY, USA 2007 & IgA agglutination of microbes, adherence and invasion of mucosal epithelial cells \\
\hline 7] & Fernandez Ml; Immunity 2003 & Internalization of IgA into intestinal epithelial cells \\
\hline 38] & Olah A; Hepatogastroenterology 2007 & Enteral nutrition reduces sepsis in patients with pancreatitis \\
\hline$[39]$ & Friedrich I; Eur J Med Res 2002 & IgM-enriched immunoglobulin preparation for immunoprophylaxis in cardiac surgery \\
\hline 40] & Fujitani K; Br J Surg. 2012 & $\begin{array}{l}\text { Prospective randomized trial of preoperative enteral immunonutrition followed by elective } \\
\text { total gastrectomy for gastric cancer }\end{array}$ \\
\hline
\end{tabular}




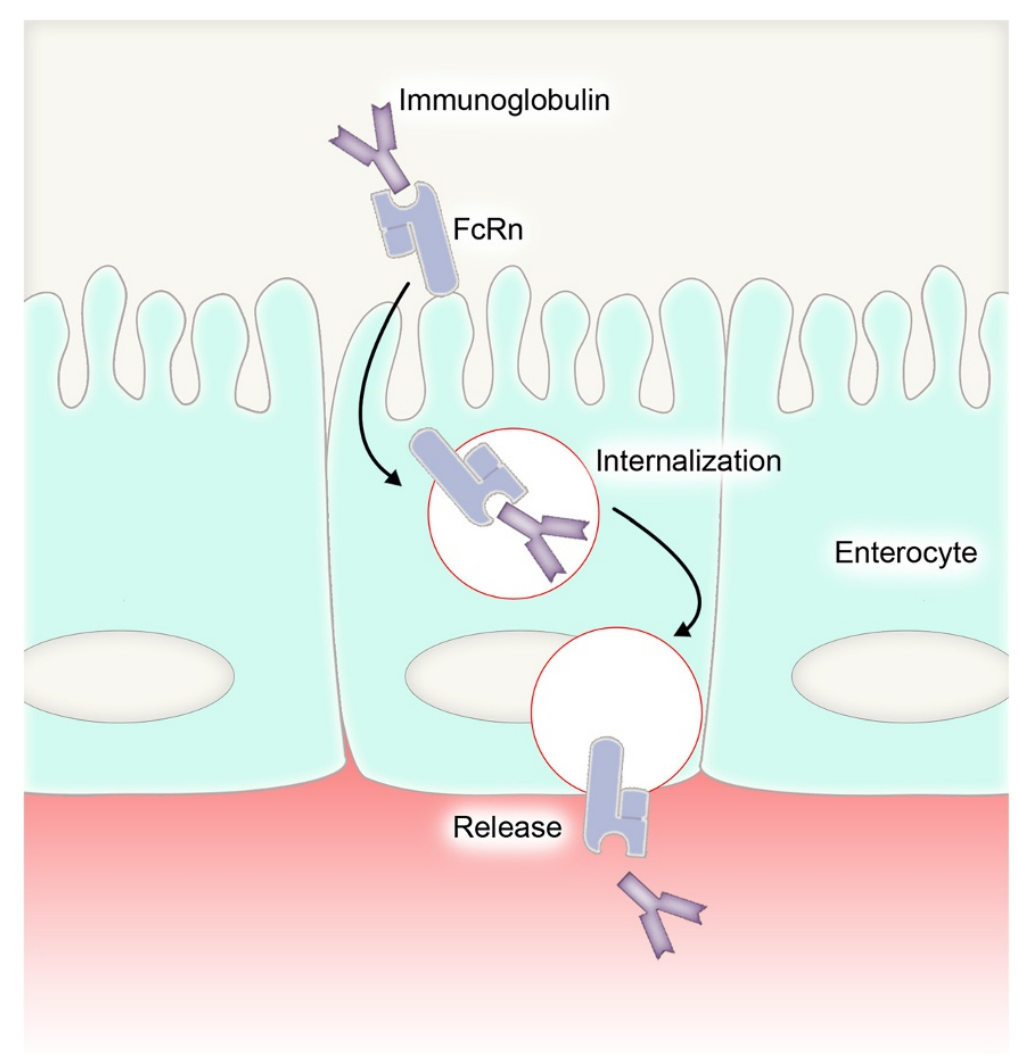

Figure $\mathbf{2}$ Immunoglobulin resorption by the neonatal Fc receptor ( $F c R n)$ in mucosal epithelia.

25 patients with thyreoidectomy and 52 patients with abdominal surgery during and after surgery, in order to evaluate the association of endotoxemia and inflammatory response in correlation with minor and major surgical interventions.

Strikingly, plasma levels of endotoxin showed an increase in the early phase of elective surgical interventions, most likely due to loss of the intestinal barrier function. In the major surgery group plasma levels of endotoxin increased immediately after application of anesthesia, whereas in the minor surgical group, endotoxin plasma levels increased after skin incision. The early increase in the major surgical group may be due to more severe anesthesiological manipulation. The relative increase in endotoxin plasma levels was significantly higher (area under the curve (AUC), $P<0.005$ ) in the major surgery group as compared to the group subjected to minor surgery. The ENC, a parameter for the ability to clear systemic endotoxin, decreased significantly during surgery in both groups, and to a significantly larger extent in patients receiving major surgery (AUC, $P<0.05)$.
Deitch et al. [35,69-73] identified the gastrointestinal tract as the major source of plasma endotoxin. However, there was no significant difference between colonic surgery and other abdominal interventions in the major surgery group related to endotoxin plasma levels or endotoxin-binding proteins (EnBP). Also, bacterial translocation was similar in both groups $[\mathrm{e}, \mathrm{f}, \mathrm{g}]$. Thus direct contamination of the peritoneal cavity during colonic surgery did not play an important role. Bacterial translocation to mesenterial lymph nodes in the major surgery group occurred in 35\%, whereas endotoxin plasma levels were elevated in $89 \%$ of patients in this group [21]. In conclusion, parts or products of Gram-negative bacteria seem to translocate more easily through the gut mucosa than whole bacteria.

Several studies have shown that the perioperative increased plasma endotoxin level activates the release of inflammatory mediators $[70,74,75]$. IL-6 increased with a distinct delay after the observed changes of endotoxin plasma levels with a significantly higher plasma level in the major surgical group (Figure 1). Similarly, another study could show that the severity of the traumatic impact 
or surgical intervention correlates with the subsequent increase in IL-6 levels, inducing a major increase of Creactive protein (CRP) $[21,23]$.

Similar results were found in 42 patients in whom endotoxin release was compared during open, versus laparoscopic, gall bladder surgery. The laparoscopic group had higher ENC, lower plasma endotoxin, and consequently a stronger postoperative acute-phase reaction with higher CRP levels. Therefore, the extent of the surgical approach with the same extent of surgical resection, without bowl resection or manipulation, correlated positively with endotoxemia and subsequently with the intensity of the acute-phase reaction.

The same results were found in aortic surgery. Mediator release (IL-6, CRP) during endovascular stent grafts of infrarenal aortic aneurysms was significantly lower when compared to that during open surgery [23]. From the beginning of the open surgical procedure, endotoxin and ENC levels increased and peaked at the end of the operation. However, patients with endovascular stent grafts had a significantly lower delayed increase of plasma endotoxin and ENC levels. Similar to the comparison of open versus laparoscopical cholecystectomy, the difference in endotoxemia depended on the surgical approach followed by a subsequent significantly lower production of acute-phase mediators in the nonintestinal surgical intervention.

In contrast to other authors Moore et al. did not find bacterial translocation after severe injury and hemorrhagic shock [76-78]. They inserted portal vein catheters for sequential blood sampling in the operating room, at $6,12,24$, and 48 hours, and 5 days postoperatively in 20 injured patients requiring emergency laparotomy. Twelve patients $(60 \%)$ arrived at the hospital in shock (SBP $<90$ torr). Eight of 212 (2\%) portal blood cultures were positive, seven cultures were presumed contaminants. Within the first 48 hours, they could not detect endotoxin in portal or systemic blood. Simultaneously obtained portal and systemic blood levels of complement fragment C3a, TNF, and IL-6 were nearly identical and not different in those patients who developed multiple organ failure. In this prospective clinical trial neither portal nor systemic bacteremia were confirmed within the first 5 days post injury, despite major torso-trauma and a high incidence of shock.

Although bacterial translocation has been consistently demonstrated in many studies and experimental models, its occurrence or detection in humans seems to be uncertain [76-82]. Secondary endotoxemia appears to be the most plausible link. However, its precise role and specific mechanisms of initiating distant organ dysfunction remain to be acknowledged. Probably the same elements that favor bacterial translocation promote escape of their toxic cell membrane from the gut lumen. With regard to these considerations, strategies have been developed to prevent endotoxin translocation by stabilizing the barrier dysfunction, that is, by selective bowel decontamination with antibiotics and oral application of Ig.

\section{Interactions of colostrum and milk immunoglobulins in the intestine}

Immune milk products have protective effects on neonatal, infant, and adult human health. The exact function and the effects of immune milk products are less clear and require further investigations. Colostrum and milk contain Ig, and a range of antimicrobial products and factors that may impact on the immune system [1,41,83-90]. These factors include leukocytes, macrophages and lymphocytes. In addition, colostrum and milk contain antibacterial enzyme lactoperoxidase, antibacterial and lytic enzyme lysozyme, oligosaccharides that function as equivalents of microbial ligands on mucosal surfaces, antimicrobial heat-stable peptides and soluble CD14, and the iron-binding antimicrobial protein, lactoferrin. Colostrum contains cytokines and growth factors, which may affect the neonatal intestinal development and intestinal immune responses to disease in adults $[90,91]$. This provides a source of energy that may impact IgG absorption in the neonate [92]. All these factors vary considerably among different species. Maternal antibodies may inhibit infant responses to vaccine administration and effect the development of the infant's immunity [93].

Most macromolecules are degraded by digestive enzymes, but a portion of macromolecule is transported through the intact intestinal wall, including protein $[94,95]$. It is therefore expected that a large part of consumed Ig is either partially or completely digested. However, a portion of the Ig remains intact and capable of binding to an antigen (Figure 2) [68].

Secretory IgA (sIgA), which is present in milk and colostrum, is the primary Ig for immune protection of the mucosal membranes, such as the intestine. This may contribute to the protective effects of these secretions [36], which have antimicrobial properties such as agglutination of microbes and neutralization of viruses. Furthermore, a non-inflammatory extracellular and intracellular immune defense by inhibition of adherence and invasion of mucosal epithelial cells has been observed $[36,68]$. Secretory IgA neutralizes pathogens in the intestinal lumen [96]. Bacterial enterotoxins can be neutralized by binding and internalization of $\operatorname{sgA}$ into intestinal epithelial cells [37]. Intracellular immunity is based on transcytosed sIgA by the enterocytes, neutralizing viral particles within the endosomic system (Figure 2) [7].

IgA has a major role in the immunosuppressive mechanisms in the intestine wall that inhibit proinflammatory responses to oral antigens [36]. This suppression is compensated by systemic immune factors, including 
systemic IgG, which results in inflammation and tissue damage once an antigen crosses the epithelial barrier to the lamina propria [36]. Any IgG localized in the lamina propria, whether from systemic sources or from the intestinal lumen, initates proinflammatory responses in the intestine wall [36]. In this context, balancing IgG-antigen immune complexes to the lamina propria for immune processing were investigated $[36,97]$.

Further on, the intestinal mucus layer does provide an important protective barrier in the interactions of the intestinal tissue with microbes [98]. Functionally intact IgG that remains in the intestinal lumen is expected to bind antigens and participate in protection of the tissue through immune exclusion. In this context, an IgG Fc binding site has been identified in association with the intestinal mucus [99-101]. The Fc binding protein can block the passage of IgG-antigen complexes to the enterocyte surface, thereby blocking its uptake and transport to the lamina propria. In this way the complexes are degraded in the intestinal lumen followed by excretion $[91,101]$.

The usual daily dose of the commercially available bovine colostrums preparation, Lactobin ${ }^{\circ}$ is 10 to $20 \mathrm{~g}$ daily. Higher doses can be used in the majority of patients because of low incidence of intolerance problems. Clinical trials have provided evidence that oral application reduces the input of lipopolysaccharides (LPS) from the gut [21]. This appears to be a major mechanism underlying its therapeutic effect in patients at risk for Gram-negative septic shock.

\section{Preoperative oral application of immunoglobulin-enriched colostrum milk in patients with abdominal surgery}

Based on findings of the postoperatively induced acutephase reaction by bacterial product translocation, strategies to prevent endotoxin translocation, that is, by oral application of Ig were developed. It is well-known that enteral application of IgA-enriched milk reduces the incidence of necrotizing enterocolitis in premature babies by stabilizing the barrier dysfunction of the immature gut [74]. In consideration of this reduction, enteral application of an Ig-enriched colostral preparation was evaluated to diminish the peri- and postoperative endotoxin translocation in patients undergoing abdominal surgery.

The impact of immunoglobulin feeding on mediator responses was analyzed in 40 patients undergoing major abdominal surgery [22]. The placebo-controlled determination of endotoxin and ENC was performed using a chromogenic modification of the limulus amebocyte test. IL-6 levels were determined by ELISA. CRP and endotoxin-binding proteins (transferrin, alpha-2-macroglobulin, albumin apo-lipoprotein A1, B, IgG, IgA and IgM) were measured nephelometrically. With abdominal surgery, the study revealed a significant reduction of circulating endotoxin levels through gut stabilization by enteral application of IgA-enriched milk with decreased inhibition of plasma ENC. The maximal loss of ENC was reduced and recovery was accelerated by colostral milk. Comparing the AUC in both groups, a highly significant improvement of ENC was found in gut barrier-stabilized patients $(P<0.05)$ [22]. As ENC indicates cumulative effects, the indirect determination of endotoxemia by assessing the ENC of plasma was more sensitive than the determination of endotoxin by a limulus amebocyte test.

Endotoxemia represents a trigger of acute-phase reaction proteins such as IL-6 and CRP [22]. IL- 6 has been shown to peak 6 hours after surgery, and CRP to peak on the second day. Lower serum levels of both proteins were measured in the colostrum group (Figure 1). Due to the wide variance, serum levels did not reach statistical significance. Similar observations were made after selective bowl decontamination. However, in the case of incomplete decontamination, a minor degree of reduction in peri- and postoperative endotoxemia was found, which did not fully explain the reduction of IL-6 plasma levels. Therefore, preoperative oral application of Igenriched colostral milk in patients with major abdominal surgery significantly reduces the amount and the duration of endotoxemia and ENC. This effect is likely due to a stabilization of the gut barrier.

These results are in accordance with those of other studies undergoing gastric and pancreatic surgery with live or heat-inactivated lactic acid bacteria [102]. The authors noted a one-month sepsis rate with live Lactobacillus plantarum 299 (L. plantarum) in one of fifteen, compared with three of seventeen patients who received heat-inactivated $L$. plantarum. Of 16 patients who received parenteral nutrition with fermentable fiber and no lactobacillus, 8 developed sepsis $(P=0.001)$. A large controlled study of patients with pancreatitis showed that enteral nutrition significantly reduced septic complications, but made no difference to the rate of multiple organ failure or death $[38,103]$. Similar results were obtained in patients undergoing liver transplantation, showing a significant reduction in sepsis rates and an improved surgical outcome [104]. Of 31 patients who received live L. plantarum 299 and fermentable fiber, 4 developed infections, compared with 11 of 34 who were given heatkilled L. plantarum 299 and fiber, and 15 of 32 were treated with selective bowel decontamination $(P=0.017)$. Well-controlled clinical studies in a total of 100 surgical patients showed that the inhibition of intestinal LPS absorption measured after bovine colostrums-concentrate applications not only reduced LPS levels in the peripheral blood, but also diminished inflammatory parameters such as IL-6 and CRP [34]. 


\section{Preoperative oral application of immunoglobulin-enriched colostrum milk in patients with cardiac surgery}

Patients were found to have elevated endotoxin plasma levels during abdominal surgery. Endotoxemia occurs commonly and can be one reason why patients develop infectious complications after surgery $[21,105]$. In patients who underwent cardiac surgery, endotoxin plasma levels correlated with the catecholamine required to obtain the necessary hemodynamic conditions during surgery [22]. Previous studies in cardiac patients demonstrated that the severity of endotoxemia is reduced by perioperative selective decontamination of the gastrointestinal tract, indicating that endotoxin translocation from the gastrointestinal tract is essentially involved $[22,106]$.

In a prospective placebo-controlled study, 30 out of the 60 patients who had cardiac surgery received immunoglobulin-enriched colostrum milk two days preoperatively. Endotoxin and ENC levels were elevated at the end of the operation. This seemed to have had a trigger function for the acute-phase response [4]. However, no reductions of endotoxin plasma levels, ENC or IL-6 levels were observed in the colostrum milk group throughout the observation period. CRP-levels in all patients peaked 48 hours after the operation but was lower in the verum group $(P=0.034)$. Similar to the abdominal surgery study, endotoxemia was detected at an early stage within an elective cardiac operation. Endotoxemia was followed by a subsequent increase in mediators of the acute-phase reaction. The prophylactic enteral application of a bovine milk preparation for two days in cardiac patients reduced postoperative plasma CRP levels, but did not reduce perioperative endotoxin, which does not support the abdominal surgery observations. The different perfusion of the bowel during cardiac surgery or the small amount of colostrum preparation administered could present one explanation. On the other hand, not all antibodies directed against pathogenic bacteria (anti-LPS) are available in Lactobin ${ }^{\circ}$. This can lead to partial reabsorption of specific LPS molecules from the intestine despite Lactobin ${ }^{\circ}$ treatment [4].

Friedrich et al. [39] randomized 41 cardiac surgical patients into two groups receiving either an IgM-enriched preparation combined with routine antibiotic prophylaxis or routine antibiotic prophylaxis plus placebo. Patients were comparable with respect to their Acute Physiology and Chronic Health Evaluation (APACHE) II score, coronary risk, comorbidity, operating time, clamping time, and ischemic time. Even though no significant endotoxin plasma levels were detected in either group, ENC levels reached significance. However, IL-6, TNF-alpha, IL-10 and TNF-R1 were not different in both groups. There were significantly fewer patients with signs of inflammation (fever, leukocytosis, hypotension) in the treated group
$(P<0.05)$, which was further related to a reduced hospitalization period (12.1 versus 13.0 days).

Another study by Fujitani et al. [40] randomized 244 patients with gastrectomy for gastric cancer into two groups: 127 patients preoperatively received immunonutrition, and 117 patients were randomized into a control group. The postoperative clinical course, infectious complications, sepsis and postoperative inflammatory mediators (for example, CRP) did not show a significant difference when comparing both groups. As the results are very different in many studies [107], the type of immunonutrition seems to play an important role. Currently, routine use of immunonutrition cannot be recommended because of insufficient evidence.

\section{Conclusion}

Enteral nutrition is not just the acquisition of calories and nitrogen, but it also offers the possibility of the acute-phase response modulation and immune-function improvement. Benmark [108] noted 75\% immune-function localization in the gastrointestinal tract. This offers nutritional science a window to modulate this system. A bacterial translocation could not always be proven in patients after major trauma. Moore et al. did find significant bacteremia or endotoxemia in their study of 20 patients [76]. However, several investigations demonstrated the impact of perioperative endotoxemia and subsequent activation of acute-phase mediators, such as IL-6 and CRP, in patients with intestinal, general, vascular and heart surgery. Bacterial translocation and endotoxemia does not only occur in patients after colonic surgery but also in all other surgical interventions. Therefore, the impact is associated with the extent of the surgical intervention and the surgical approach (open surgery versus minimal invasive treatment). Preventive protection of the mucosal barrier function by selective decontamination with antibiotics was proven to be beneficial. However, selection and mutation of bacteria interdict a non-selective application of antibiotics. Therefore, nutritional strategies are favorable as they were proven to be effective and they do not promote selective breeding of resistant bacteria. The main actions include an antibacterial effect and the modulation of the immune response. Polyvalent bovine colostrum concentrates are able to neutralize LPS, that is, endotoxins arising from Gramnegative bacterial pathogen, and can inhibit activation of acute-phase mediators.

The concentration in colostrum of specific antibodies against pathogens is raised by immunizing cows with these pathogens or their antigens. Immune milk products are supplements made of such hyperimmune colostrum or antibodies enriched from this milk. These products can be used to give effective specific protection against different enteric diseases and are commercially 
available for animal farming. They were also proven to be effective in balancing gastrointestinal microbial flora and in prophylaxis against various infectious diseases in humans. Positive results have been obtained with products targeting Rotavirus, Shigella flexneri, Escherichia coli, Clostridium difficile, Streptococcus mutans, Cryptosporidium parvum and Helicobacter pylori. Clinical studies are currently in progress to evaluate the efficacy of immune milks in the prevention and treatment of various human infections, including those caused by antibioticresistant bacteria. Immune milk products are promising examples of health-promoting functional foods.

\section{Abbreviations \\ AUC: Area under the curve; CRP: C-reactive protein; ELISA: Enzyme-linked immunosorbent assay; EnBP: Endotoxin-binding protein; ENC: Endotoxin neutralizing capacity; IL: Interleukin; Ig: Immunoglobulin; slgA: Secretory immunoglobulin A; TNF: Tumor necrosis factor.}

\section{Competing interests}

All authors disclose any potential financial, professional, or personal conflict that are relevant to this manuscript. We disclose funding received for this work from the National Institutes of Health $(\mathrm{NIH})$ Wellcome Trust, and others.

\section{Authors' contributions}

All authors were involved in drafting or revision of the manuscript and intellectual input. All authors read and approved the final manuscript.

\section{Author details}

${ }^{1}$ Medical Faculty, Department of General, Visceral, and Thoracal Surgery, Asclepios Harz Hospitals, Goslar, Germany. ${ }^{2}$ Medical Faculty, Department of General, Visceral-, and Pediatric Surgery, Heinrich Heine Universität Düsseldorf, Germany University of Düsseldorf, Dusseldorf, Germany. ${ }^{3}$ Department of Trauma Surgery, Klinikum rechts der Isar, Technische Universität München, Munich, Germany. ${ }^{4}$ Medical Faculty Department of Dermatology, Heinrich Heine Universität Düsseldorf, Germany University of Düsseldorf, Dusseldorf, Germany. ${ }^{5}$ Medical Faculty Department of Radiation Oncology, Heinrich Heine Universität Düsseldorf, Germany University of Düsseldorf, Moorenstrasse 5, Duesseldorf D-40225, Germany. 'Klinik für Allgemein-, Viszeral-, Gefäß- und Unfallchirurgie, Krankenhaus St. Joseph. Propsteistr. 2, Essen-Werden 45239, Germany.

Received: 17 January 2013 Accepted: 11 November 2013 Published: 23 November 2013

\section{References}

1. Adar T, Ben Ya'acov A, Lalazar G, et al: Oral administration of immunoglobulin G-enhanced colostrum alleviates insulin resistance and liver injury and is associated with alterations in natural killer T cells. Clin Exp Immunol 2012, 167:252-260.

2. Berger D, Boelke E, Huegel H, Seidelmann M, Hannekum A, Beger HG: New aspects concerning the regulation of the post-operative acute phase reaction during cardiac surgery. Clin Chim Acta 1995, 239:121-130.

3. Boelke E, Jehle PM, Storck M, Nothnagel B, Stanescu A, Orth K: Endotoxin release and endotoxin neutralizing capacity during colonoscopy. Clin Chim Acta 2001, 303:49-53.

4. Boelke E, Orth K, Jehle PM, et al: Enteral application of an immunoglobulin-enriched colostrum milk preparation for reducing endotoxin translocation and acute phase response in patients undergoing coronary bypass surgery-a randomized placebo-controlled pilot trial. Wien Klin Wochenschr 2002, 114:923-928.

5. Dong W, Cai B, Pena G, et al: Ethyl pyruvate prevents inflammatory responses and organ damage during resuscitation in porcine hemorrhage. Shock 2010, 34:205-213

6. Engelberger RP, Pittet YK, Henry $\mathrm{H}$, et al: Acute endotoxemia inhibits microvascular nitric oxide-dependent vasodilation in humans. Shock 2011, 35:28-34.
7. Hsiao HB, Wu JB, Lin H, Lin WC: Kinsenoside isolated from Anoectochilus formosanus suppresses LPS-stimulated inflammatory reactions in macrophages and endotoxin shock in mice. Shock 2011, 35:184-190.

8. Kalil AC, LaRosa SP, Gogate J, Lynn M, Opal SM: Influence of severity of illness on the effects of eritoran tetrasodium (E5564) and on other therapies for severe sepsis. Shock 2011, 36:327-331.

9. Kauh E, Mixson L, Malice MP, et al: Prednisone affects inflammation, glucose tolerance, and bone turnover within hours of treatment in healthy individuals. Eur J Endocrinol 2012, 166:459-467.

10. Kim OY, Monsel A, Bertrand M, Cavaillon JM, Coriat P, Adib-Conquy M: Translocation of bacterial NOD2 agonist and its link with inflammation. Crit Care 2009, 13:R124.

11. Qiao Z, Li Z, Li J, Lu L, LV Y: Bacterial translocation and change in intestinal permeability in patients after abdominal surgery. J Huazhong Univ Sci Technolog Med Sci 2009, 29:486-491.

12. Quesnell RR, Klaessig S, Watts JL, Schukken YH: Bovine intramammary Escherichia coli challenge infections in late gestation demonstrate a dominant antiinflammatory immunological response. J Dairy Sci 2012, 95:117-126.

13. Ramakers BP, Riksen NP, van der Hoeven JG, Smits P, Pickkers P: Modulation of innate immunity by adenosine receptor stimulation. Shock 2011, 36:208-215.

14. Roumen RM, Frieling JT, van Tits HW, van der Vliet JA, Goris RJ: Endotoxemia after major vascular operations. J Vasc Surg 1993, 18:853-857.

15. Sharma B, Srivastava S, Singh N, Sachdev V, Kapur S, Saraya A: Role of probiotics on gut permeability and endotoxemia in patients with acute pancreatitis: a double-blind randomized controlled trial. $J$ Clin Gastroenterol 2011, 45:442-448.

16. Shih $\mathrm{HC}$, Huang MS, Lee $\mathrm{CH}$ : Relation of signal in mononuclear cell with endotoxin response and clinical outcome after trauma. Am J Emerg Med 2012, 30:405-411.

17. Sugiura S, Ishihara $Y$, Komatsu T, et al: Valproic acid increases susceptibility to endotoxin shock through enhanced release of high-mobility group box 1. Shock 2011, 36:494-500.

18. van Meurs M, Wulfert FM, Jongman RM, et al: Hemorrhagic shock-induced endothelial cell activation in a spontaneous breathing and a mechanical ventilation hemorrhagic shock model is induced by a proinflammatory response and not by hypoxia. Anesthesiology 2011, 115:474-482.

19. Zhou QQ, Yang DZ, Luo YJ, Li SZ, Liu FY, Wang GS: Over-starvation aggravates intestinal injury and promotes bacterial and endotoxin translocation under high-altitude hypoxic environment. World J Gastroenterol 2011, 17:1584-1593.

20. Marshall JC, Christou NV, Horn R, et al: The microbiology of multiple organ failure. Arch Surg 1988, 123:309-315.

21. Bolke $E$, Jehle $P M$, Graf $M$, et al: Inflammatory response during abdominal and thyroid surgery: a prospective clinical trial on mediator release. Shock 2001, 16:334-339.

22. Bolke E, Jehle PM, Orth K, Steinbach G, Hannekum A, Storck M: Changes of gut barrier function during anesthesia and cardiac surgery. Angiology 2001, 52:477-482.

23. Bolke E, Jehle PM, Storck M, et al: Endovascular stent-graft placement versus conventional open surgery in infrarenal aortic aneurysm: a prospective study on acute phase response and clinical outcome. Clin Chim Acta 2001, 314:203-207.

24. Kapoor MC, Ramachandran TR: Inflammatory response to cardiac surgery and strategies to overcome it. Ann Card Anaesth 2004, 7:113-128.

25. Sharpe SM, Qin X, Lu Q, et al: Loss of the intestinal mucus layer in the normal rat causes gut injury but not toxic mesenteric lymph nor lung injury. Shock 2010, 34:475-481.

26. Buttenschoen K, Buttenschoen DC, Berger D, et al: Endotoxemia and acutephase proteins in major abdominal surgery. Am J Surg 2001, 181:36-43.

27. Fujita T, Imai T, Anazawa S: Influence of modest endotoxemia on postoperative antithrombin deficiency and circulating secretory immunoglobulin a levels. Ann Surg 2003, 238:258-263.

28. Maring JK, Zwaveling JH, Klompmaker IJ, van der Meer J, Slooff MJ: Selective bowel decontamination in elective liver transplantation: no improvement in endotoxaemia, initial graft function and post-operative morbidity. Transpl Int 2002, 15:329-334.

29. Nieuwenhuijzen GA, Deitch EA, Goris RJ: Infection, the gut and the development of the multiple organ dysfunction syndrome. Eur J Surg 1996, 162:259-273. 
30. Kudsk KA, Minard G, Croce MA, et al: A randomized trial of isonitrogenous enteral diets after severe trauma. An immune-enhancing diet reduces septic complications. Ann Surg 1996, 224:531-540. discussion 540-3.

31. Moore FA, Feliciano DV, Andrassy RJ, et al: Early enteral feeding, compared with parenteral, reduces postoperative septic complications. The results of a meta-analysis. Ann Surg 1992, 216:172-183.

32. Guillou PJ: Enteral versus parenteral nutrition in acute pancreatitis. Baillieres Best Pract Res Clin Gastroenterol 1999, 13:345-355.

33. Cardinale F, Chinellato I, Caimmi S, et al: Perioperative period: immunological modifications. Int J Immunopathol Pharmacol 2011, 24(Suppl 3):S3-S12.

34. Struff WG, Sprotte G: Bovine colostrum as a biologic in clinical medicine: a review. Part I: biotechnological standards, pharmacodynamic and pharmacokinetic characteristics and principles of treatment. Int J Clin Pharmacol Ther 2007, 45:193-202.

35. Deitch EA, Xu D, Kaise VL: Role of the gut in the development of injuryand shock induced SIRS and MODS: the gut-lymph hypothesis, a review. Front Biosci 2006, 11:520-528.

36. Brandtzaeg $P$, Johansen FE: IgA and intestinal homeostasis. In Mucosal Immune Defense: Immunoglobulin A. Edited by Kaetzel CS. New York, NY, USA: Springer; 2007:221-268

37. Fernandez MI, Pedron T, Tournebize R, Olivo-Marin JC, Sansonetti PJ, Phalipon A: Anti-inflammatory role for intracellular dimeric immunoglobulin a by neutralization of lipopolysaccharide in epithelial cells. Immunity 2003, 18:739-749.

38. Olah A, Belagyi T, Poto L, Romics L Jr, Bengmark S: Synbiotic control of inflammation and infection in severe acute pancreatitis: a prospective, randomized, double blind study. Hepatogastroenterology 2007, 54:590-594.

39. Friedrich I, Silber RE, Baumann B, Fischer C, Holzheimer RG: IgM-enriched immunoglobulin preparation for immunoprophylaxis in cardiac surgery. Eur J Med Res 2002, 7:544-549.

40. Fujitani K, Tsujinaka T, Fujita J, Miyashiro I, Imamura H, Kimura Y, Kobayashi K, Kurokawa Y, Shimokawa T, Furukawa H: Osaka Gastrointestinal Cancer Chemotherapy Study Group: Prospective randomized trial of preoperative enteral immunonutrition followed by elective total gastrectomy for gastric cancer. Br J Surg 2012, 99:621-629. doi:10.1002/bjs.8706.

41. Pakkanen R, Aalto J: Growth factors and antimicrobial factors of bovine colostrum. Int Diary J 1997, 7:285-297.

42. Solomons NW: Modulation of the immune system and the response against pathogens with bovine colostrum concentrates. Eur J Clin Nutr 2002, 56(Suppl 3):S24-S28.

43. Bodammer P, Maletzki C, Waitz G, Emmrich J: Prophylactic application of bovine colostrum ameliorates murine colitis via induction of immunoregulatory cells. J Nutr 2011, 141:1056-1061.

44. Bolke $E_{\text {, Jehle } P M}$, Trautmann $M$, et al: Different acute-phase response in newborns and infants undergoing surgery. Pediatr Res 2002, 51:333-338.

45. Carol A, Witkamp RF, Wichers HJ, Mensink M: Bovine colostrum supplementation's lack of effect on immune variables during short-term intense exercise in well-trained athletes. Int J Sport Nutr Exerc Metab 2011, 21:135-145.

46. Kaushik S, Trivedi SS, Jain A, Bhattacharjee J: Unusual changes in colostrum composition in lactating Indian women having medical complications during pregnancy. A pilot study. Indian J Clin Biochem 2002, 17:68-73.

47. Lascelles AK: The immune system on the ruminant mammary gland and its role in the control of mastitis. J Dairy Sci 1979, 62:154-167.

48. Shing CM, Adams MJ, Fassett RG, Coombes JS: Nutritional compounds influence tissue factor expression and inflammation of chronic kidney disease patients in vitro. Nutrition 2011, 27:967-972.

49. Elfstrand L: Immunoglobulins, growth factors and growth hormone in bovine colostrum and the effects of processing. Int Dairy J 2002, 12:879-887

50. Butler JE, Kehrli ME: Immunoglobulins and immunocytes in the mammary gland and its secretions. In Mucosal Immunology. 3rd edition. Edited by Mestecky J, Lamm M, Strober W, Bienenstock J, McGhee JR, Mayer L. Burlington, MA, USA: Elsevier Academic Press; 2005:1764-1793.

51. Wheeler TT, Hodgkinson AJ, Prosser CG, Davis SR: Immune components of colostrum and milk-a historical perspective. J Mammary Gland Biol Neoplasia 2007, 12:237-247.

52. Butler JE: Immunoglobulins of the mammary secretions. In Lactation: A Comprehensive Treatise. Edited by Larson BL, Smith VR. New York, NY, USA: Academic Press; 1974:217-255.
53. McClelland DBL: Antibodies in milk. J Reprod Fertil 1982, 65:537-543.

54. Butler JE: Bovine immunoglobulins: an augmented review. Vet Immunol Immunopathol 1983, 4:43-152.

55. Chernishov VP, Slukvin II: Mucosal immunity of the mammary gland and immunology of mother/newborn interrelation. Arch Immunol Ther Exp (Warsz) 1990, 38:145-164.

56. Larson BL: Immunoglobulins of the mammary secretions. In Advanced Dairy Chemistry: Proteins. 2nd edition. Edited by Fox PF. London, UK: Elsevier Applied Science; 1992:231-254.

57. Telemo E, Hanson LA: Antibodies in milk. J Mammary Gland Biol Neoplasia 1996, 1:243-249.

58. Korhonen H, Marnila P, Gill HS: Milk immunoglobulins and complement factors. Br J Nutr 2000, 84(Suppl 1):S75-S80.

59. Hanson L, Silfverdal SA, Stromback L, et al: The immunological role of breast feeding. Pediatr Allergy Immunol 2001, 12(Suppl 14):15-19.

60. Lilius EM, Marnila P: The role of colostral antibodies in prevention of microbial infections. Curr Opin Infect Dis 2001, 14:295-300.

61. Tizard I: The protective properties of milk and colostrum in non-human species. Adv Nutr Res 2001, 10:139-166.

62. Uruakpa FO, Ismond MAH, Akobundu ENT: Colostrum and its benefits: A review. Nutr Rev 2002, 22:755-767.

63. Hurley WL: Immunoglobulins of the mammary secretions. In Advanced Dairy Chemistry: Proteins. 3rd edition. Edited by Fox PF, McSweeney PLH. New York, NY, USA: Kluwer Academic/Plenum Publishers; 2003:421-447. 1, Part A.

64. Van de Perre P: Transfer of antibody via mother's milk. Vaccine 2003, 21:3374-3376.

65. Gapper LW, Copstake DEJ, Otter DE, Indyk HE: Analysis of bovine immunoglobulin $\mathrm{G}$ in milk, colostrum and dietary supplements: A review. Anal Bioanal Chem 2007, 389:93-109.

66. Stelwagen K, Carpenter E, Haigh B, Hodgkinson A, Wheeler TT: Immune components of bovine colostrum and milk. J Anim Sci 2009, 87(Suppl 13):3-9.

67. Brandtzaeg P: The mucosal immune system and its integration with the mammary glands. J Pediatr 2010, 156(Suppl 2):S8-S15.

68. Roopenian DC, Akilesh S: FcRn: the neonatal Fc receptor comes of age. Nat Rev Immunol 2007, 7:715-725

69. Deitch EA: Multiple organ failure. Pathophysiology and potential future therapy. Ann Surg 1992, 216:117-134.

70. Deitch EA: Cytokines yes, cytokines no, cytokines maybe? Crit Care Med 1993, 21:817-819.

71. Deitch EA, Winterton J, Li M, Berg R: The gut as a portal of entry for bacteremia. Role of protein malnutrition. Ann Surg 1987, 205:681-692.

72. Deitch EA, Xu D, Franko L, Ayala A, Chaudry $I H$ : Evidence favoring the role of the gut as a cytokine-generating organ in rats subjected to hemorrhagic shock. Shock 1994, 1:141-145.

73. Buerke M, Lemm H, Dietz S, Werdan K: Pathophysiology, diagnosis, and treatment of infarction-related cardiogenic shock. Herz 2011, 36:73-83.

74. Clements WD, Parks R, Erwin P, Halliday MI, Barr J, Rowlands BJ: Role of the gut in the pathophysiology of extrahepatic biliary obstruction. Gut 1996, 39:587-593.

75. Coon CA, Warne RW, Martin LB: Acute-phase responses vary with pathogen identity in house sparrows (Passer domesticus). Am J Physiol Regul Integr Comp Physiol 2011, 300:R1418-R1425.

76. Moore EE, Jones TN: Benefits of immediate jejunostomy feeding after major abdominal trauma-A prospective, randomized study. J Trauma 1986, 26:874-881.

77. Moore FA, Moore EE, Jones TN, et al: TEN versus TPN following major abdominal trauma-Reduced septic morbidity. J Trauma 1989, 29:916-923.

78. Moore FA, Moore EE, Poggetti R, McAnena OJ, Peterson VM, Abernathy CM, Parsons PE: Gut bacterial translocation via the portal vein: a clinical perspective with major torso trauma. J Trauma 1991, 31(5):629-636. discussion 636-8. PubMed PMID: 2030509.

79. Baker JW, Deitch EA, Berg RD, et al: Hemorrhagic shock induces bacterial translocation from the gut. J Trauma 1988, 28:896-906.

80. Redan JA, Rush BF, McCullough JN, et al: Organ distribution of radiolabeled enteric Escherichia coli during and after hemorrhagic shock. Ann Surg 1990, 211:663-668.

81. Rush BF, Redan JA, Flanagan JJ, et al: Does the bacteremia observed in hemorrhagic shock have clinical significance? Ann Surg 1989, 210:342-347. 
82. Rush BF, Sori AJ, Murphy TF, et al: Endotoxemia and bacteremia during hemorrhagic shock. Ann Surg 1988, 207:549-554.

83. Barrington GM, Parish SM: Bovine neonatal immunology. Vet Clin North Am Food Anim Pract 2001, 17:463-476.

84. Blum JW: Nutritional physiology of neonatal calves. J Anim Physiol Anim Nutr (Berl) 2006, 90:1-11.

85. Gill H: Dairy products and the immune function in the elderly. In Functional Dairy Products. Edited by Mattila-Sandholm T, Saarela M. New York, NY, USA: CRC Press; 2003:133-168.

86. Hanson LA, Korotkova M, Telemo E: Human milk: Its components and their immunobiologic functions. In Mucosal Immunology. 3rd edition. Edited by Mestecky J, Bienenstock J, Lamm ME, Mayer L, McGhee JR, Strober W. Amsterdam, The Netherlands: Elsevier Academic Press; 2005:1795-1827.

87. Lonnerdal B: Nutritional and physiologic significance of human milk proteins. Am J Clin Nutr 2003, 77:1537S-1543S.

88. Mehta R, Petrova A: Biologically active breast milk proteins in association with very preterm delivery and stage of lactation. J Perinatol 2010, 31:58-62.

89. Newburg DS, Walker WA: Protection of the neonate by the innate immune system of developing gut and of human milk. Pediatr Res 2007, 61:2-8.

90. Playford RJ, Macdonald CE, Johnson WS: Colostrum and milk-derived peptide growth factors for the treatment of gastrointestinal disorders. Am J Clin Nutr 2000, 72:5-14.

91. Siccardi D, Turner JR, Mrsny RJ: Regulation of intestinal epithelial function: a link between opportunities for macromolecular drug delivery and inflammatory bowel disease. Adv Drug Deliv Rev 2005, 57:219-235.

92. Bikker P, Kranendonk G, Gerritsen R, et al: Absorption of orally supplied immunoglobulins in neonatal piglets. Livest Sci 2010, 134:139-142.

93. Siegrist CA: Mechanisms by which maternal antibodies influence infant vaccine responses: review of hypotheses and definition of main determinants. Vaccine 2003, 21:3406-3412.

94. Hardin JA, Kimm MH, Wirasinghe M, Gall DG: Macromolecular transport across the rabbit proximal and distal colon. Gut 1999, 44:218-225.

95. Weiner ML: Intestinal transport of some macromolecules in food. Food Chem Toxicol 1988, 26:867-880

96. Davids BJ, Palm JE, Housley MP, et al: Polymeric immunoglobulin receptor in intestinal immune defense against the lumen-dwelling protozoan parasite Giardia. J Immunol 2006, 177:6281-6290.

97. Rojas R, Apodaca G: Immunoglobulin transport across polarized epithelia cells. Nat Rev Mol Cell Biol 2002, 3:1-12.

98. Guarner F, Malagelada JR: Gut flora in health and disease. Lancet 2003, 361:512-519.

99. Harada N, lijima S, Kobayashi K, et al: Human IgGFc binding protein (FcgammaBP) in colonic epithelial cells exhibits mucin-like structure. J Biol Chem 1997, 272:15232-15241.

100. Kobayashi K, Blaser MJ, Brown WR: Identification of a unique IgG Fc binding site in human intestinal epithelium. J Immunol 1989, 143:2567-2574.

101. Kobayashi K, Ogata H, Morikawa M, et al: Distribution and partial characterisation of IgG Fc binding protein in various mucin producing cells and body fluids. Gut 2002, 51:169-176.

102. Olah A, Belagyi T, Issekutz A, Gamal ME, Bengmark S: Randomized clinical trial of specific lactobacillus and fibre supplement to early enteral nutrition in patients with acute pancreatitis. Br J Surg 2002, 89:1103-1107.

103. Olah A, Pardavi G, Belagyi T, Nagy A, Issekutz A, Mohamed GE: Early nasojejunal feeding in acute pancreatitis is associated with a lower complication rate. Nutrition 2002, 18:259-262.

104. Rayes N, Seehofer D, Hansen S, et al: Early enteral supply of lactobacillus and fiber versus selective bowel decontamination: a controlled trial in liver transplant recipients. Transplantation 2002, 74:123-127.

105. Zhang $C, X u Y G$, Duan $X N$, et al: Role of granulocyte colony-stimulating factor in paclitaxel-induced intestinal barrier breakdown and bacterial translocation in rats. Chin Med J (Engl) 2011, 124:1870-1875.

106. Schneider M, Valentine S, Hegde RM, Peacock J, March S, Dobb GJ: The effect of different bypass flow rates and low-dose dopamine on gut mucosal perfusion and outcome in cardiac surgical patients. Anaesth Intensive Care 1999, 27:13-19.
107. Mudge $L$, Isenring $E$, Jamieson GG: Immunonutrition in patients undergoing esophageal cancer resection. Dis Esophagus 2011, 24:160-165.

108. Benmark S: Prospect for a new and rediscovered form of therapy: probiotic and phage. In Fighting Infection in the 21st Century. Edited by Andrew PW, Oystron P, Smith GL, Stewart-Tull DE. London: Blackwells; 2000:97-132.

doi:10.1186/2047-783X-18-50

Cite this article as: Orth et al:: Preventively enteral application of immunoglobulin enriched colostrums milk can modulate postoperative inflammatory response. European Journal of Medical Research 2013 18:50.

\section{Submit your next manuscript to BioMed Central and take full advantage of:}

- Convenient online submission

- Thorough peer review

- No space constraints or color figure charges

- Immediate publication on acceptance

- Inclusion in PubMed, CAS, Scopus and Google Scholar

- Research which is freely available for redistribution

Submit your manuscript at www.biomedcentral.com/submit
C) Biomed Central 